\title{
Conserved Spatial Learning in Cooled Rats in Spite of Slowing of Dentate Field Potentials
}

\author{
Edvard I. Moser and Per Andersen \\ Department of Neurophysiology, University of Oslo, 0317 Oslo, Norway
}

\begin{abstract}
Behaviorally induced brain temperature changes have significant effects on field potentials recorded in the hippocampal formation. All components of the field potential are slowed during cooling. Field excitatory postsynaptic potentials ( $f$ EPSPs) are often reduced, while the population spike is increased in this state. To investigate whether such synaptic alterations affect hippocampus-dependent learning, we have compared the effects of reduced brain temperature on dentate field potentials and spatial learning in a Morris water maze. Rats were implanted with thermistors in the brain. A subset of the rats received electrodes for field potential recording in the perforant path-granule cell synapses of the dentate gyrus. After recovery, the rats were cooled by swimming in a pool of water. This invariably led to a brain temperature reduction of several degrees centigrade and a delay of the extracellular response. In addition, the field potential changed as described above. The effect of these changes on spatial learning in a second pool, the water maze, was determined by first cooling and then reheating each rat to a given level of brain temperature prior to each spatial training session. In spite of marked changes in dentate field potentials, all rats trained at brain temperatures above $30^{\circ} \mathrm{C}$ learned to find the submerged platform similarly well. The speed of acquisition and the final precision of search behavior were also similar in these rats. Only rats that had been cooled below $30^{\circ} \mathrm{C}$ failed to locate the hidden target. These animals also showed clear evidence of motor impairment. The results indicate that there is no optimal temperature for spatial learning within the range of physiological brain temperatures. Learning must be tolerant to significant slowing of synaptic transmission in cortical tissue.
\end{abstract}

[Key words: hippocampus, spatial learning, memory, brain temperature, dentate gyrus, field potentials, synchrony]

Changes in behavior may be coupled to changes in brain temperature. Brain temperature increase of $1-2.5^{\circ} \mathrm{C}$ within $10-20$ min is seen during behavior involving high muscular activity, such as feeding and forced running in rats (Abrams and Hammel, 1964, 1965; Moser et al., 1993a) and bicycling in humans (Nielsen, 1988). A similar elevation of brain temperature is

\footnotetext{
Received Nov. 9, 1993; revised Jan. 18, 1994; accepted Jan. 27, 1994.

This research was supported by the Norwegian Medical Research Council (NAVF/ RMF), Grants 377.91-040, 326.91-024, and 326.88-007. We acknowledge Bruce Piercey, Trond Reppen, Tore Eriksen, Eva Aaboen Hansen, and Luc Scholte for technical assistance.

Correspondence should be addressed to Edvard Moser, Department of Neurophysiology, Institute of Basic Medical Sciences, University of Oslo, Post Box 1104 Blindern, 0317 Oslo, Norway.

Copyright (C) 1994 Society for Neuroscience $0270-6474 / 94 / 144458-09 \$ 05.00 / 0$
}

observed when rats learn about the environment by exploration (Moser et al., 1993a). Since rats move during most other learning episodes as well, a coupling between learning and enhanced brain temperature may be the rule. One exception is repeated swimming in a water maze, which often reduces the brain temperature by as much as $5^{\circ} \mathrm{C}$ (Moser et al., 1993a).

Temperature alterations have significant effects on the electrical properties of nerve cells in vitro. Cooling slows down and enhances intra- and extracellularly recorded action potentials because spike repolarization is more temperature sensitive than the rising phase of the action potential (Schoepfle and Erlanger, 1941; Hodgkin and Katz, 1949). Similar changes are seen in field potentials in that the population spike is augmented by cooling (Andersen, 1960; Schiff and Somjen, 1985). On the other hand, cooling reduces synaptic potentials (Andersen, 1960; Schiff and Somjen, 1985), probably because the transmitter release is slowed down (Katz and Miledi, 1965). Warming, up to $41^{\circ} \mathrm{C}$, produces exactly opposite effects.

The demonstration of temperature-induced changes in vitro has employed temperatures well outside the physiological range. However, corresponding field potential changes have recently been observed as a result of behaviorally induced temperature changes as well (Moser et al., 1993a). A resting rat has a core temperature of $37-38^{\circ} \mathrm{C}$ (Gordon, 1990). During rest, this is usually also the temperature at the base of the brain (E. I. Moser, I. Mathiesen, and P. Andersen, unpublished observations). During exploration, the brain temperature increases (Moser et al., 1993a). This is responsible for a reduced latency of the extracellular response, a larger field excitatory postsynaptic potential (f-EPSP), and a smaller population spike. Conversely, during swimming in the water-maze task, the brain temperature drops, causing exactly opposite effects on the electrical signals. Thus, in many situations, learning is accompanied not only by brain temperature alteration, but also by significant temperatureevoked changes in hippocampal signal transmission. Given the importance of the state of synaptic transmission for learning (Morris et al., 1988), an obvious question is, therefore, to what extent these changes affect the learning process.

Spatial learning in a water maze depends on the hippocampus (Morris et al., 1982, 1990; Sutherland et al., 1983). To investigate whether brain temperature reduction affects not only hippocampal field potentials but also spatial learning, we have measured dentate ficld potentials and acquisition of a water-maze task within a brain temperature range of $28-39^{\circ} \mathrm{C}$. This range probably covers the temperature variation of rats living in their natural habitat, with swimming in cold water as part of the behavioral repertoire. The temperature was recorded close to the hippocampal formation because, although body and brain temperature normally follow each other (Lewis et al., 1972), 


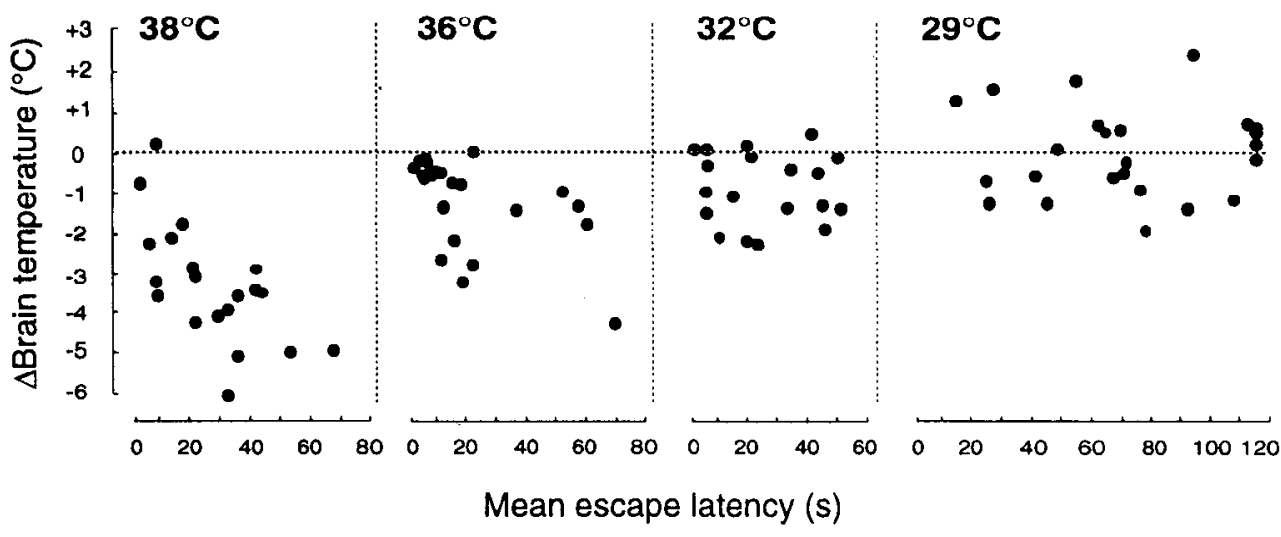

Figure 1. Effect of swim time on brain temperature reduction. The temperature change from the start of trial 1 to the completion of trial 4 (same session) is shown as a function of the mean escape latency on those four trials for rats starting at $38^{\circ} \mathrm{C}, 36^{\circ} \mathrm{C}, 32^{\circ} \mathrm{C}$, or $29^{\circ} \mathrm{C}$. Each point represents one session, but each rat is represented by several points.

rapid cooling of the skin by water may affect the superficial parts of the brain more than deep colonic tissue.

\section{Materials and Methods}

Subjects and surgical procedure. Forty-five male Long-Evans rats (250$400 \mathrm{gm}$; Möllegaards Avlslaboratorium, Denmark) were housed in groups of four to six in transparent polycarbonate cages $(59 \times 38 \times 20 \mathrm{~cm})$ with food and water available ad libitum. They were kept on a 12:12 hr light/dark schedule and tested in the light phase.

Thirty-five rats were operated. The animals were anesthetized with a mixture (Equithesin) of $153 \mathrm{mg}$ of chloral hydrate, $35 \mathrm{mg}$ of pentobarbital, and $75 \mathrm{mg}$ of $\mathrm{MgSO}_{4}$ per kilogram of body weight, and placed in a stereotaxic frame. The skull was exposed, and access holes were drilled. A thermistor $(0.5 \mathrm{~mm}$ diameter; $111-802$ EAJ-B01, Fenwal Electronics, Milford, MA) was implanted in the cortex of the contralateral hemisphere just above the dorsal hippocampus $(n=29)$ or at the base of the brain $(n=6)$. Before implantation, each thermistor was calibrated in a water bath against a precision thermometer. In six animals, we also implanted a bipolar stimulation electrode (SNEX 100, Rhodes Medical Instr. Inc., Woodland Hills, CA) in the right angular bundle (7.5-8.0 $\mathrm{mm}$ posterior and $4.3 \mathrm{~mm}$ lateral to bregma) as well as an insulated tungsten recording electrode in the ipsilateral dentate hilus or granule cell layer $(4.0 \mathrm{~mm}$ posterior and $2.6 \mathrm{~mm}$ lateral to bregma). The electrode and thermistor leads were connected to a socket fastened to the skull with dental acrylic and the rats were allowed to recover for at least 1 week.

Water-maze apparatus. Behavioral testing was conducted in a Morris water maze (Morris, 1984), a circular PVC tank (198 cm diameter, 50 $\mathrm{cm}$ deep) with a featureless, white inner surface, located in a large, welllit room with numerous visual cues. The pool was filled to a depth of $40 \mathrm{~cm}$ with water of $25 \pm 1^{\circ} \mathrm{C}$, to which 2 liter of milk was added. Midway between center and periphery, there was an escape platform at a fixed location, consisting of a white plastic disk (11 cm diameter) on top of a steel cylinder $(6 \mathrm{~mm}$ diameter) at a fixed location. The height of the platform was pneumatically regulated (Buresova et al., 1986; Markowska et al., 1993) and could be moved vertically between an upper, available position $(1.5 \mathrm{~cm}$ below the water surface) and a lower, unavailable position ( $22 \mathrm{~cm}$ below the surface). Switching the pressure on or off resulted in gentle vertical movement of the cylinder with the disk (taking $5 \mathrm{sec}$ from bottom to top). A platform of fixed height was used in the nonspatial phase of the experiment. On tests with a visible platform, the platform was raised $1.5 \mathrm{~cm}$ above the water surface and a stripe of colored tape was fastened around its upper perimeter.

training procedure. The spatial-learning experiment was run in two replicates. The rats (26 implanted and 10 unimplanted subjects) were trained in blocks (sessions) of four trials, separated from the next by 15 sec. Each trial was begun by releasing the rat into the water, with its face toward the pool wall, at one of 12 randomly varied and equally spaced start positions. The position of the rat was monitored by a vertically oriented video camera $2 \mathrm{~m}$ above the water maze. The camera was connected to a computer, which identified the black head of the swimming rat and stored its position at $10 \mathrm{~Hz}$. The data could be retrieved for later analysis. The program tracked the position of the rat until the rat entered the platform. If the rat failed to find the platform within $120 \mathrm{sec}$, it was guided onto it. The rat was always left on the platform for $30 \mathrm{sec}$.

The experiment consisted of a nonspatial and a spatial stage. During the first six sessions (nonspatial stage), white, opaque curtains were drawn around the pool to occlude distal spatial cues. Two sessions, separated by at least $4 \mathrm{hr}$, were conducted daily. The top of the platform was always $1.5 \mathrm{~cm}$ below the water surface. The position of the platform was varied from trial to trial, each quadrant being represented in each four-trial block. All rats were normothermic when released into the pool. After completion of the nonspatial pretraining stage, the average latencies to find the platform on the two last sessions were used to assign the 26 operated rats to four temperature groups, so that the animals with the highest and the lowest latencies were equally distributed among the different groups. The four groups were later tested at starting temperatures of $29^{\circ} \mathrm{C}(n=5), 32^{\circ} \mathrm{C}(n=9), 36^{\circ} \mathrm{C}(n=5)$, and $38^{\circ} \mathrm{C}(n=$ $7)$, respectively. Rats with mean escape latencies above a preset criterion of $100 \mathrm{sec}$ on the last two sessions were excluded from the study.

In the second stage of the experiment, the curtains were removed and spatial training started. Five sessions (one per day) with the pressureregulated platform were conducted. The platform was always located in the center of the southeast quadrant of the pool. On the first trial of each session, the platform was kept in its lower position for the first 40 sec. The platform was then raised to its upper position (still submerged) for the rest of the session. The initial unavailability of the platform permitted daily measurement of the spatial precision of the search behavior. The brain temperature (thermistor resistance) of the operated rats was measured before release into the pool and after termination of the fourth trial by connecting the head plug to the recording equipment while holding the rat. The temperature at the outset was used for most analyses. Because the brain temperature falls (or remains constant) during the swimming (Fig. 1), this gives a conservative estimate of the lower temperature limit for learning in the water maze.

One day after the spatial-learning phase was completed, two rats were further tested on four consecutive spatial probe tests in which the platform was made available after $60 \mathrm{sec}$. Each test was conducted at a different brain temperature. During these tests, field potentials and search behavior were recorded simultaneously.

Cooling. In order to avoid uneven stress exposure, all experimental rats were cooled to $32^{\circ} \mathrm{C}$ and then either kept at that temperature or rewarmed to a certain, new temperature. About 20 min prior to each session in the second stage of the experiment, each implanted rat, after being connected to the recording equipment, swam in a tank $(60 \mathrm{~cm}$ diameter) with cold water $\left(10-13^{\circ} \mathrm{C}\right)$ until the brain temperature passed $32^{\circ} \mathrm{C}(<6 \mathrm{~min}, n=21)$ or $29^{\circ} \mathrm{C}(<10 \mathrm{~min}, n=5)$. Twelve of the rats cooled to $32^{\circ} \mathrm{C}$ were then reheated to $36^{\circ} \mathrm{C}$ or $38^{\circ} \mathrm{C}$, respectively, by blowing warm air $\left(45^{\circ} \mathrm{C}\right)$ into their cages or by using a heating lamp. The remaining rats (the $32^{\circ} \mathrm{C}$ and $29^{\circ} \mathrm{C}$ groups) rested for an equivalent period after cooling. The unoperated control rats were not cooled.

Electrophysiological recording. In six different rats, dentate field potentials were recorded in response to constant perforant-path stimulation (100-500 $\mu \mathrm{A}, 100 \mu \mathrm{sec}, 0.2 \mathrm{~Hz}$ ) while the rats were swimming in the water maze. Brain temperature (thermistor resistance) was recorded simultaneously $(0.2 \mathrm{~Hz})$. Both signals were sampled at $35 \mathrm{kHz}$ by a computer. Four of the rats were untrained and swam for 3.5-5 min without an escape platform (total of 10 trials). They were not cooled 
A

Figure 2. Field potential changes in the dentate gyrus during swimming. $A$, Superimposed perforant-path dentate field potentials (averages of 12) taken (solid line) of $5 \mathrm{~min}$ of swimming in a water maze at $18^{\circ} \mathrm{C}$. There was no platform in the pool. $B$, Brain temperature recorded at the surface of the dorsal hippocampus and maximum f-EPSP slope, population spike amplitude, and population spike latency of field potentials recorded in the perforant pathdentate synapses. Same experiment as in $A$. $C$, The relation between the brain temperature change from start to termination of swimming and the change in maximum f-EPSP slope, spike amplitude, and spike latency in four rats (total of 10 experiments). Points connected by a line are from the same experiment. Error bars are SEM. The thick, shaded lines represent the regression lines fitted by the method of least squares. during the first (broken line) and the last
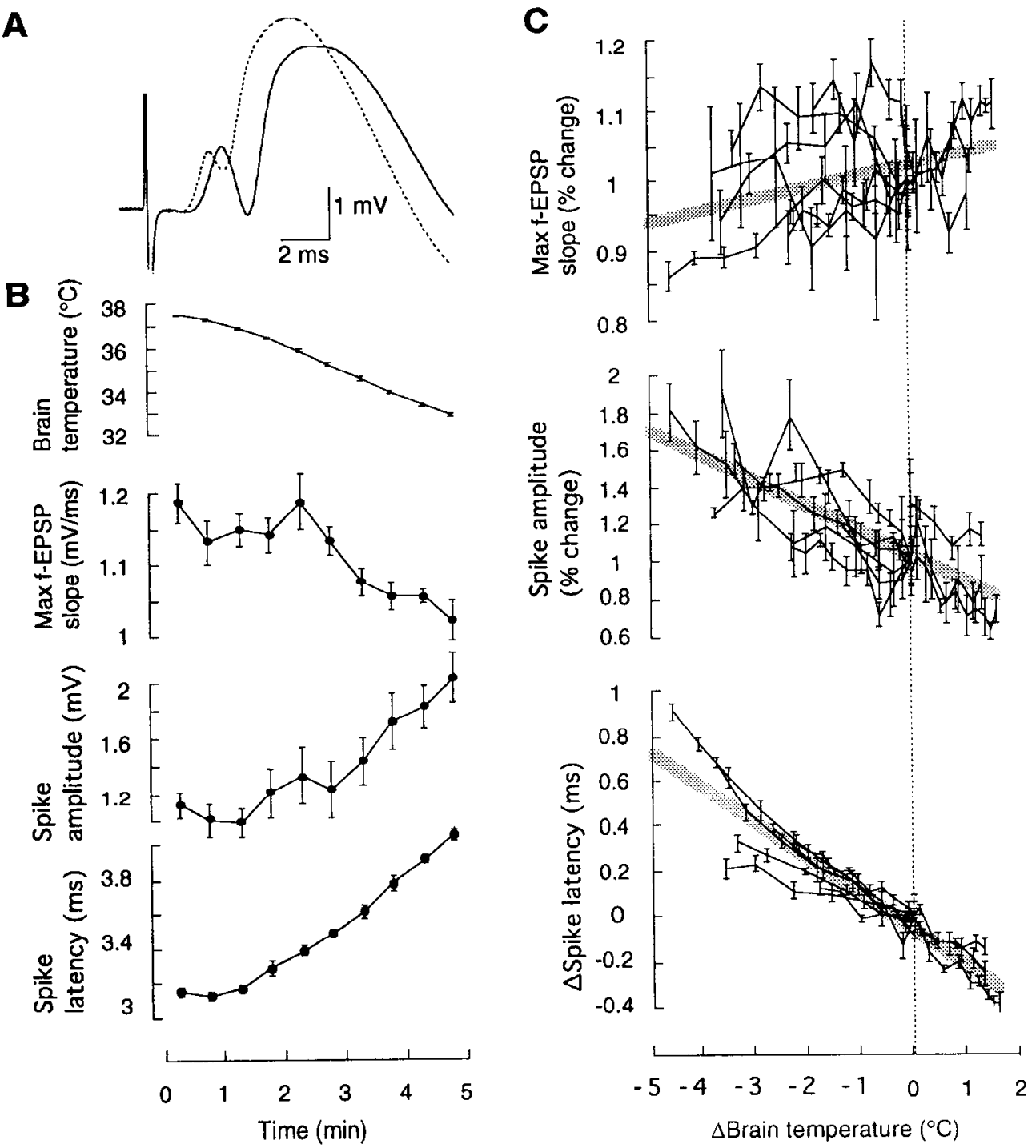

before swimming. Two other rats had completed the pretraining and spatial training phases of the experiment (sessions 1-11). In these rats, field potentials were recorded during search behavior in the water maze after the rats had been cooled to $28^{\circ} \mathrm{C}$ or $32^{\circ} \mathrm{C}$, followed by rest or rewarming. The platform was kept in its lower position (unavailable) during the first $60 \mathrm{sec}$ of each of the latter trials in order to assess any preference for the platform region. Computer programs were used to calculate the maximum f-EPSP slope and the population spike amplitude and latency. The maximum f-EPSP slope was chosen because calculation of f-EPSPs from cursors at fixed latencies mixes up slope changes with temperature-related changes in f-EPSP latency (Moser, Mathiesen, and Andersen, unpublished observations). The population spike was taken as the vertical distance between the peak and a joint tangent to the preceding and succeeding positivities. The spike latency was defined as the time from stimulus onset to spike peak.

Histology. A few hours after behavioral testing was finished, the rats were killed with an overdose of Equithesin and perfused intracardially with saline and $4 \%$ formaldehyde. The brains were removed and stored in formaldehyde. Frozen sections $(25 \mu \mathrm{m})$ were cut coronally and every 10 th section stained with cresyl violet.

Statistical procedures. The results were evaluated with repeated-measures analysis of variance. To reduce the heterogeneity of variance, the latency data were $\log$ transformed prior to the analysis. Repeated-measures designs assume that covariance matrices are spherical, that is, consist of a set of variables that are orthogonal (all covariances are zero) with constant variance (Vasey and Thayer, 1987; Winer et al., 1991). To correct for violation of this assumption, we multiplied the numerator and denominator degrees of freedom of the $F$ ratio by Huynh and Feldt's (1976) estimate of $\epsilon$ (these products are the df values reported).

\section{Results}

Histology

The thermistors necessarily caused some unilateral neocortical damage $\left(<2 \mathrm{~mm}^{3}\right)$, which included parts of the hindlimb area of the somatosensory cortex, occipital cortical area 2, and parietal cortical area 1 (Zilles, 1985). Five rats had small traces of unilateral damage $(<1 \%)$ to the CA1 or CA3 of the hippocampus. Less damage was caused by the electrodes. Previous tests have shown that neocortical and hippocampal lesions of this magnitude do not substantially affect learning in the water maze (Moser et al., 1993b).

\section{Brain cooling and changes in field potentials during acquisition of the water-maze task}

Brain cooling. Swimming in water of $25^{\circ} \mathrm{C}$ caused the brain temperature to fall gradually, often by several degrees centigrade (Fig. 1). The amount of cooling was greater the higher the brain temperature at the start of trial 1 , and the longer the duration of the swimming. The relation to start temperature and escape 

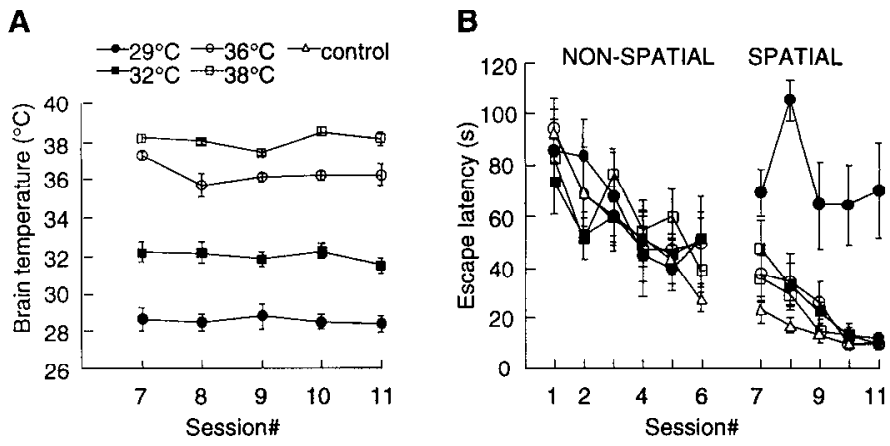

Figure 3. Effect of brain temperature on acquisition of the water-maze task. The mean temperature at the start of the first trial $(A)$ and the latency to locate the platform $(B)$ are shown as a function of training session for the four predetermined temperature groups $\left(29^{\circ} \mathrm{C}, 32^{\circ} \mathrm{C}\right.$, $36^{\circ} \mathrm{C}, 38^{\circ} \mathrm{C}$ ) and the normothermic unoperated control group. Sessions 1-6 (nonspatial phase) were conducted with curtains around the pool, and the platform position varied from trial to trial. During the remaining sessions (spatial phase), the curtains were removed and the platform position was fixed. The rats were cooled only in the spatial part of the experiment. Error bars show SEM.

latency was investigated on the data from the spatial phase of the experiment (sessions 7-11).

In the rats with start temperatures set at $38^{\circ} \mathrm{C}$, four consecutive trials with mean escape latencies below $20 \mathrm{sec}$ led to a median temperature reduction of $2.2^{\circ} \mathrm{C}$. On the two longest trials (mean latencies of 57 and $71 \mathrm{sec}$ ), the temperature fell $5.0^{\circ} \mathrm{C}$ and $4.9^{\circ} \mathrm{C}$, respectively. The correlation between escape latency and brain temperature reduction was significant $[r(18)=0.65$, $p<0.005$ ]. In the rats starting at $36^{\circ} \mathrm{C}$, the brain temperature fell by $0.7^{\circ} \mathrm{C}$ and $1.6^{\circ} \mathrm{C}$ (median values) following four trials with mean escape latencies below $20 \mathrm{sec}$ and above $50 \mathrm{sec}$, respectively. Again, the correlation between escape latency and temperature reduction was significant $[r(22)=0.53, p<0.01]$. In the $32^{\circ} \mathrm{C}$ and $29^{\circ} \mathrm{C}$ groups, however, temperature changes were not related to escape latency $(|r|$ values $<0.04)$. The respective median temperature reductions of these groups were $0.6^{\circ} \mathrm{C}$ and $0.1^{\circ} \mathrm{C}$.

Temperature-induced field potential changes. Field potentials and brain temperature were recorded on 10 trials in four naive rats that swam for 3.5 or $5 \mathrm{~min}$ in the water maze without an escape platform. Swimming in water of $18^{\circ} \mathrm{C}, 25^{\circ} \mathrm{C}$, or $40^{\circ} \mathrm{C}$ had a marked effect on both the brain temperature and the field potentials (Fig. 2). The largest effect was on the latency of both the f-EPSP and the population spike. The population spike was delayed by about almost $1 \mathrm{msec}$ following a brain temperature reduction of $5^{\circ} \mathrm{C}$. The relation between brain temperature and spike latency was nearly linear $[r(70)=-0.94, p<0.001]$. Cooling also led to a pronounced enhancement of the amplitude of the population spike [correlation with brain temperature: $r(70)=-0.75, p<0.001]$. In contrast, the maximum f-EPSP slope decreased with declining temperature $[r(70)=0.35, p<$ 0.005 ], but this effect was smaller (usually $<10 \%$ ) and clearly more variable. Indeed, on three trials, an enhanced f-EPSP slope was observed in spite of reduccd brain temperature (up to $3^{\circ} \mathrm{C}$ ).

\section{Effects of brain cooling on spatial-learning ability}

Nonspatial pretraining. Rats learn more than spatial relationships when performing a water-maze task. Cooling may affect nonspatial processes as well. In order to investigate the effects on spatial learning as specifically as possible; we pretrained the

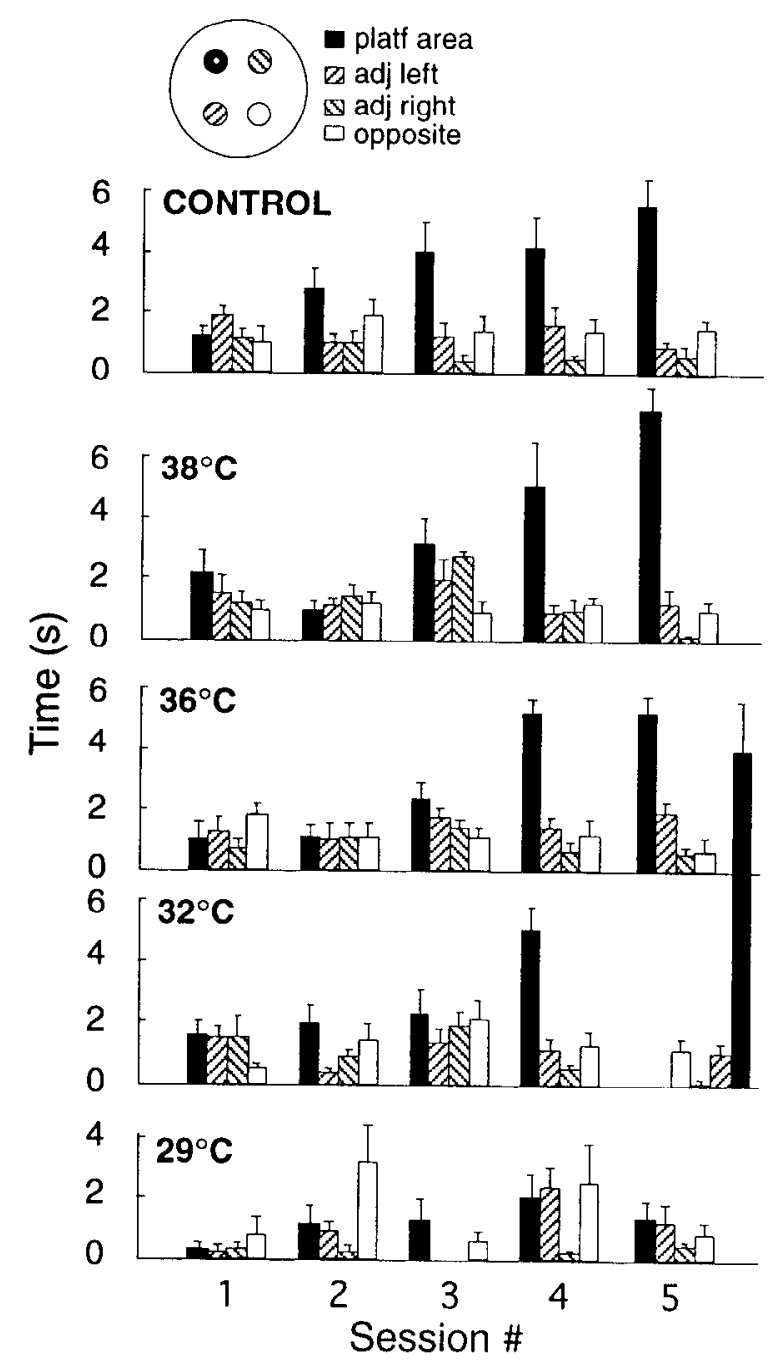

Figure 4. Performance on daily spatial probe tests by rats swimming at different brain temperatures. The swim time was measured inside a circular area ( $52 \mathrm{~cm}$ diameter) around the center of each quadrant (training quadrant, adjacent left, adjacent right, and the quadrant opposite to the training quadrant; shown at $t o p$ ). In the spatial phase of the experiment, the platform had been located consistently in the center of the training quadrant. The mean time spent inside the central circles of each quadrant is shown for each cooled group $\left(29^{\circ} \mathrm{C}, 32^{\circ} \mathrm{C}, 36^{\circ} \mathrm{C}, 38^{\circ} \mathrm{C}\right)$ and for the normothermic unoperated control group on each session of the spatial part of the study. Error bars are SEM. Random search gives an expected swim time of $2.7 \mathrm{sec}$ inside a given circle.

rats on a nonspatial version of the water-maze task until the animals had learned to swim away from the pool walls and search for the platform. During the nonspatial training, the latency to climb the platform decreased from $85.4 \pm 4.6 \mathrm{sec}$ (mean \pm SEM) on session 1 to $42.0 \pm 4.4 \mathrm{sec}$ on session 6 [session effect: $F(5,155)=14.3 ; p<0.001 ;$ Fig. 3]. The latencies of the four animal groups created on the basis of day 3 escape latencies did not differ at any stage of the pretraining (group and group $x$ session effects: $F$ values $<1.2$ ). Five rats failed to pass the $100 \mathrm{sec}$ criterion on day 3 and werc not tested further.

Spatial learning: escape latencies. All rats except those cooled to $29^{\circ} \mathrm{C}$ learned where the hidden platform was located. The $29^{\circ} \mathrm{C}$ group showed long escape latencies throughout the spatial stage (means above $60 \mathrm{sec}$ on all sessions), a result that is poorer than at the end of the pretraining phase where they were not cooled ( $51.0 \mathrm{sec}$ on session 6$)$. The escape latencies of the other 


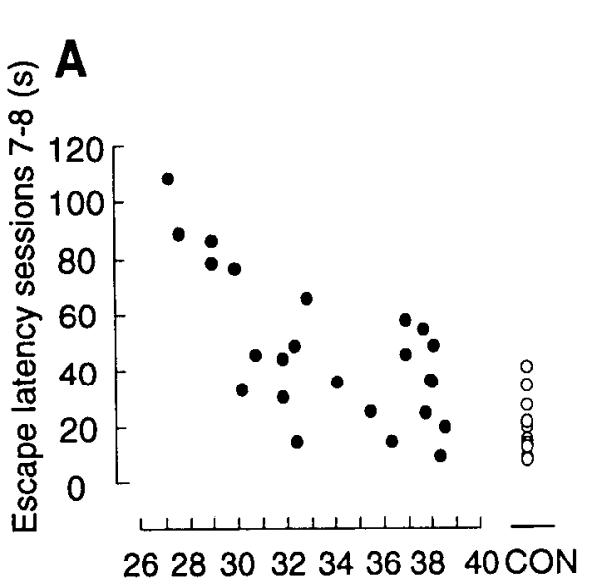

$2628303234363840 \mathrm{CON}$
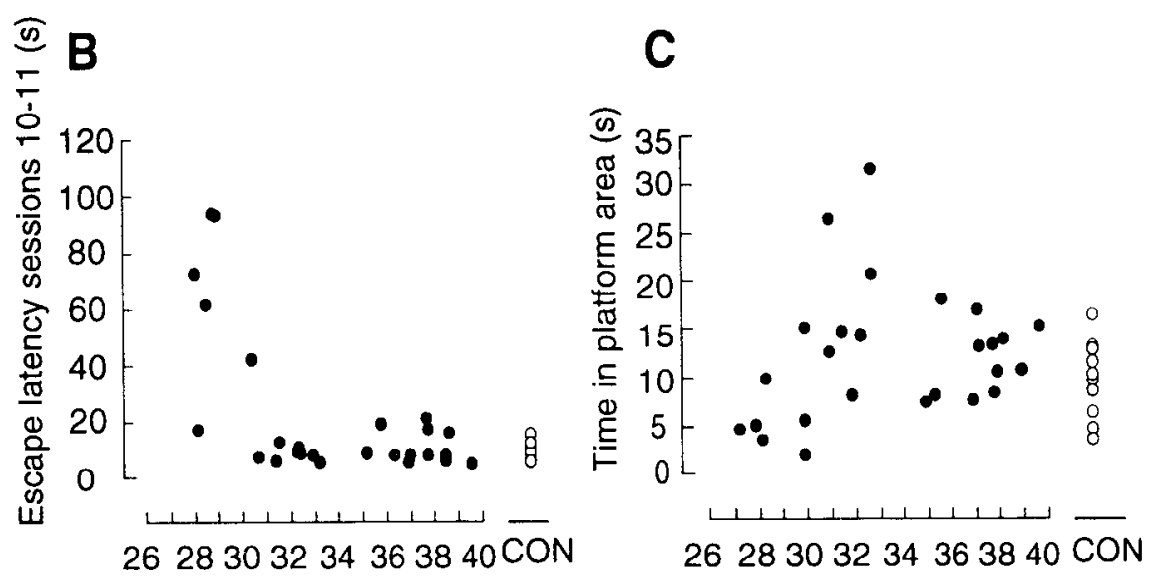

Brain temperature $\left({ }^{\circ} \mathrm{C}\right)$

Figure 5. Relation between the brain temperature and learning performance. Scatter plots show the brain temperature at the start of swimming, versus the mean latency in sessions 7 and $8(A)$, the mean latency in sessions 10 and $11(B)$, and the time swum inside a small circle $(52 \mathrm{~cm}$ diameter) around the previous platform position on the final spatial probe test (session 11) (C). Each filled circle represents an individual rat. The performance of the unoperated rats (open circles) is shown for comparison.

three cooled groups, starting trial 1 at $32^{\circ} \mathrm{C}, 36^{\circ} \mathrm{C}$, or $38^{\circ} \mathrm{C}$, and of the noncooled control group were not different at any stage of the acquisition of the spatial task (Fig. 3; and see Fig. $5 A, B$ ). On the two final sessions, these groups had escape latencies of $13.2 \pm 4.9 \mathrm{sec}, 10.1 \pm 2.5 \mathrm{sec}, 9.8 \pm 2.1 \mathrm{sec}$, and $9.2 \pm 1.4$ sec, respectively. Within each of the latter groups, no relation was observed between brain temperature and escape latencies either early (see Fig. $5 A$ ) or late (see Fig. $5 B$ ) in the training phase.

An ANOVA on the data from the spatial phase revealed significant session $[F(4,124)=19.3, p<0.001]$ and group $[F(4,31)$ $=18.0, p<0.001]$ effects, but no group $\times$ session interaction $[F(16,124)=1.1]$. Subscquent analyses performed on pairs of groups showed that the group effect in the main analysis reflected the difference between the $29^{\circ} \mathrm{C}$ group and each of the four other groups ( $p$ values $<0.001$ ). Except for a significant difference between the $32^{\circ} \mathrm{C}$ group and the unoperated controls $(p=0.02)$, there were no other group differences.

Spatial precision of the search behavior. One way to estimate the spatial memory is to see whether trained animals search at the target location on a trial where the platform is unavailable (Morris, 1984). Here, we have measured such spatial preference during the first $40 \mathrm{sec}$ of each session, when the platform was in the low position. We measured the time the rats spent in two equally large areas defined by concentric circles $(52$ and $74 \mathrm{~cm}$ diameter) around the platform center and around the centers of the three other quadrants (Fig. 4).

Again, the performance of the $29^{\circ} \mathrm{C}$ group was poor, whereas all the other groups learned to search at the platform site (Fig. 4). None of the groups showed any spatial bias on the first spatial trial. At the end of the training period (session 11), all groups except the $29^{\circ} \mathrm{C}$ group spent considerably more time in the central area $(52 \mathrm{~cm}$ diameter) of the platform quadrant (from 5.2 to $10.9 \mathrm{sec}$ ) than in the center of the other quadrants (averages from 2.3 to $3.1 \mathrm{sec}$ ). Within the platform quadrant, each of these groups swam more in the central area than in the equally large outer ring (from $3.4 \mathrm{sec}$ to $6.3 \mathrm{sec}$ in the latter area). There was no significant correlation between brain temperature and time spent in the central area of the platform quadrant in the rats starting at $32^{\circ} \mathrm{C}, 36^{\circ} \mathrm{C}$, or $38^{\circ} \mathrm{C}[r(19)=-0.39, p>0.05$; Fig. $5 \mathrm{C}$. In contrast, the rats cooled to $29^{\circ} \mathrm{C}$ showed only marginal preference for the correct area (1.4 sec and $1.9 \mathrm{sec}$ in the central and surrounding areas of the platform quadrant, respectively, vs an average of $0.82 \mathrm{sec}$ in the other quadrant centers). However, at least four of the five rats in this group did search more in the correct than in the incorrect half of the pool
Rat 1

Session 10

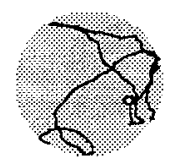

$28.4^{\circ} \mathrm{C}$

Figure 6. Swim paths of each of the five rats cooled to $29^{\circ} \mathrm{C}$. The swim paths were recorded during the initial $40 \mathrm{sec}$ of the two final sessions (session 10 and session 11), when the platform was unavailable.
Rat 2

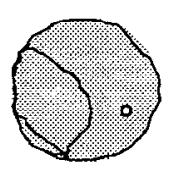

$30.0^{\circ} \mathrm{C}$

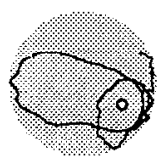

$27.4^{\circ} \mathrm{C}$
Rat 3

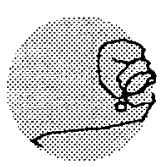

$28.0^{\circ} \mathrm{C}$

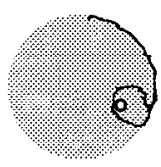

$29.8^{\circ} \mathrm{C}$
Rat 4

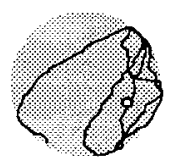

$28.3^{\circ} \mathrm{C}$

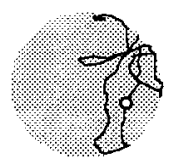

$28.6^{\circ} \mathrm{C}$
Rat 5

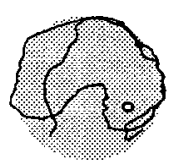

$27.3^{\circ} \mathrm{C}$

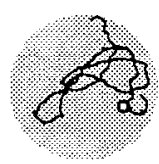

$28.7^{\circ} \mathrm{C}$ 


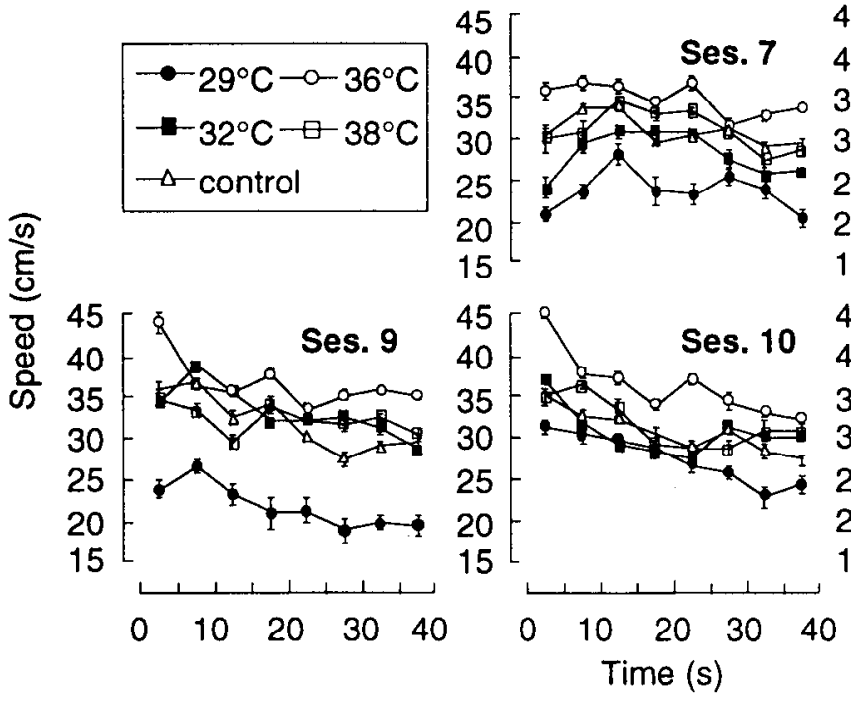

on the two last sessions (Fig. 6), suggesting that spatial learning was not entirely blocked.

A closer statistical analysis confirmed that the odd group was the rats cooled to $29^{\circ} \mathrm{C}$. The ANOVA gave significant effects of session $\times$ quadrant $[F(9,290)=16.1, p<0.001]$, group $\times$ session $\times$ quadrant $[F(37,290)=2.1, p<0.001]$, session $\times$ quadrant $\times$ circle $[F(11,335)=4.3, p<0.001]$, and group $\times$ session $\times$ quadrant $\times$ circle $[F(43,335)=1.6, p<0.02]$. Subsequent single-session analyses showed significant group $\times$ quadrant $[F(8,59)=5.8, p<0.001]$ and group $\times$ quadrant $\times$ circle $[F(7,52)=4.2, p=0.001]$ effects only on the final session. In this session, significant quadrant $\times$ circle effects appeared in all groups but the $29^{\circ} \mathrm{C}$ group.

\section{Motor, sensory, and motivational effects of brain cooling}

Speed of swimming. A large part of the impairment of the $29^{\circ} \mathrm{C}$ group might reflect the effect of cooling on motor performance rather than on spatial learning. Thus, we calculated the speed of swimming during the initial $40 \mathrm{sec}$ of each session when the platform was unavailable.

Only extensive cooling (to $29^{\circ} \mathrm{C}$ ) had a significant influence on the speed with which the rats swam (Fig. 7). The $36^{\circ} \mathrm{C}$ and $38^{\circ} \mathrm{C}$ groups swam at speeds comparable to that of the unoperated control group. The $32^{\circ} \mathrm{C}$ group swam slightly slower on the first spatial session (session 7). On session 7 , when all groups swam equally widely in the entire pool, the respective average speeds of the $29^{\circ} \mathrm{C}, 32^{\circ} \mathrm{C}, 36^{\circ} \mathrm{C}$, and $38^{\circ} \mathrm{C}$ groups and the unoperated group were $23.8,28.2,34.9,31.2$, and $31.1 \mathrm{~cm} / \mathrm{sec}$. There was a moderate positive correlation between brain temperature and speed of swimming on session $7[r(22)=0.41, p$ $<0.05$ ]. On sessions 8 and 9 , only the rats cooled to $29^{\circ} \mathrm{C}$ deviated from the rest. On the two final sessions, the difference between the $29^{\circ} \mathrm{C}$ group and the other ones had almost disappeared, due to lower speed in many of the warmer animals while they were searching in the platform area. In general, the speed of swimming was highest in the middle sessions (sessions 8-10) and in the initial part of the trials (sessions 8-11).

Once again, the statistical analyses showed a difference between the $29^{\circ} \mathrm{C}$ group and the other groups. An ANOVA of the speed data on sessions 7 through 11 showed a significant group effect $[F(4,27)=9.3, p<0.001]$. Comparison of pairs of groups
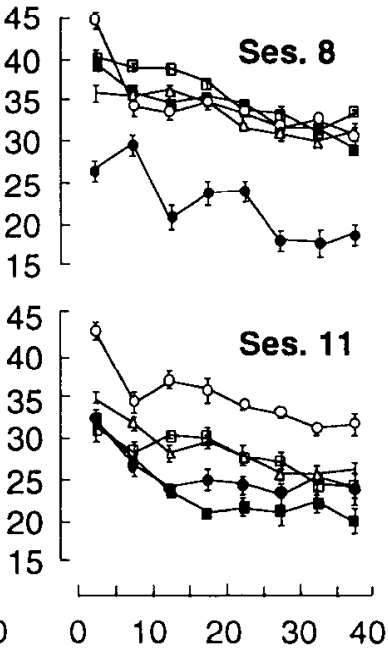

Figure 7. Speed of swimming as a function of brain tempcraturc. The speed of swimming for each group is shown as a function of time since start of swimming (blocks of $5 \mathrm{sec}$ ) for each session. Error bars are SEM. The data were collected from the initial $40 \mathrm{sec}$ of each session, when no platform was available. revealed that the group effect reflected the difference between the $29^{\circ} \mathrm{C}$ group and each of the other groups ( $F$ values $>6.1$, $p$ values $<0.05$ ). In addition, the $36^{\circ} \mathrm{C}$ rats had a higher speed than the others ( $F$ values $>5.4, p$ values $<0.05$ ). The main analysis also showed significant effects of session $[F(4,108)=$ $8.1, p<0.001]$, time $[F(7,189)=31.7, p<0.001]$, and group $\times$ session $[F(16,108)=3.6, p<0.001]$, but no group $\times$ time interaction $(F<1)$.

Visible platform. To evaluate further the effect of sensory and motor factors, we tested a subset of the rats (the $29^{\circ} \mathrm{C}$ and $36^{\circ} \mathrm{C}$ groups and two of the rats cooled to $32^{\circ} \mathrm{C}$ ) with a visible platform (Morris, 1984). This task is nonspatial but the motor and mo-
A

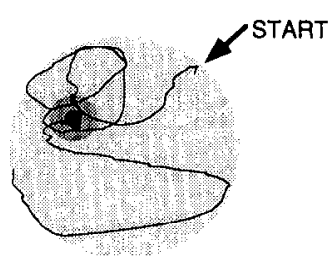

C

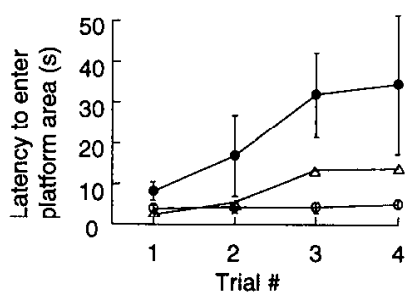

B

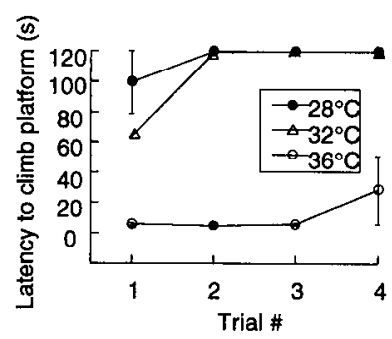

D $\hat{E}$

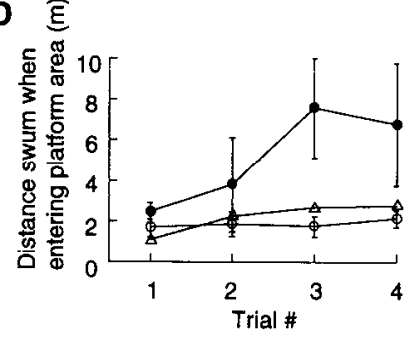

Figure 8. Effect of brain temperature on swimming to a visible platform. A, Typical swim path of a rat cooled to $29^{\circ} \mathrm{C}$ on a the first trial with a visible platform. The rat swims directly toward the platform (black), but fails to climb onto it. $B$, Latency to climb the visible escape platform successfully on four consecutive trials in rats starting at brain temperatures close to $29^{\circ} \mathrm{C}, 32^{\circ} \mathrm{C}$, and $36^{\circ} \mathrm{C}$. C, Latency to reach an imaginary circle $(52 \mathrm{~cm}$ diameter) around the visible platform, defined as the area shown in dark gray in $A$. $D$, Length of the swim path from start to the point where the rat reaches the circle around the platform. Error bars are SEM. 


$\begin{array}{llll}\text { Trial } 1 & \text { Trial } 2 & \text { Trial } 3 & \text { Trial } 4 \\ 38.4^{\circ} \mathrm{C} & 34.7^{\circ} \mathrm{C} & 31.8^{\circ} \mathrm{C} & 28.4^{\circ} \mathrm{C}\end{array}$

A
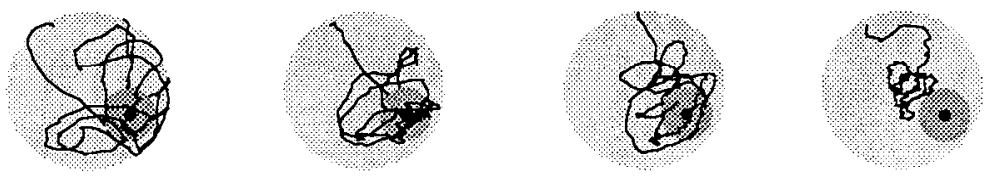

B
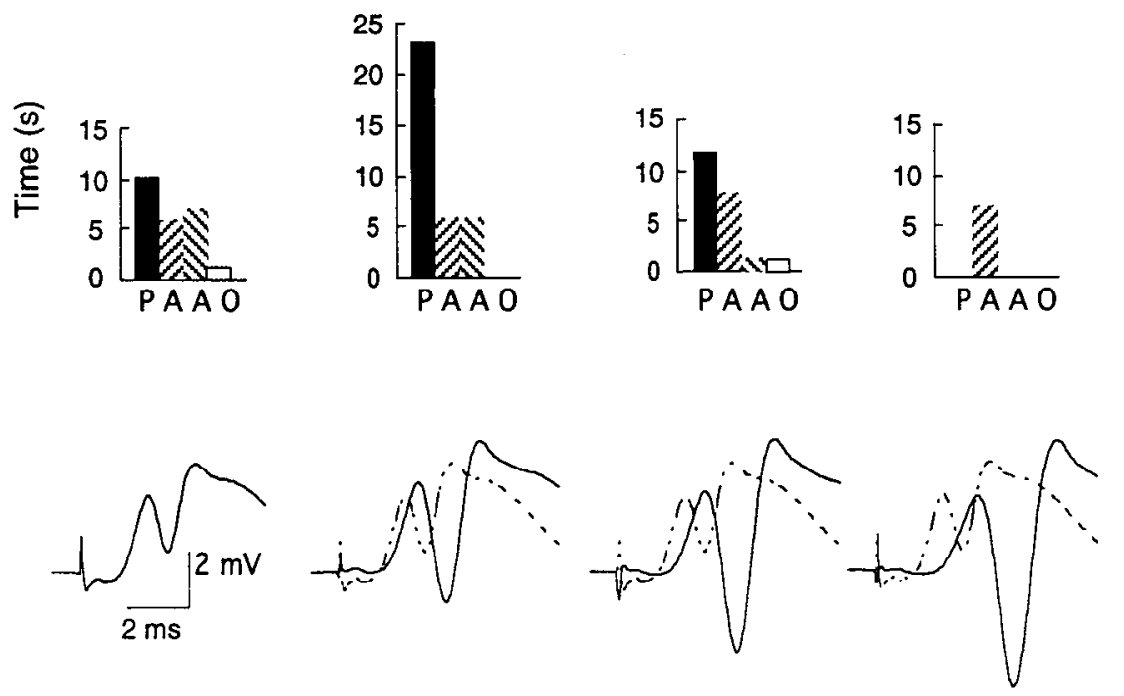

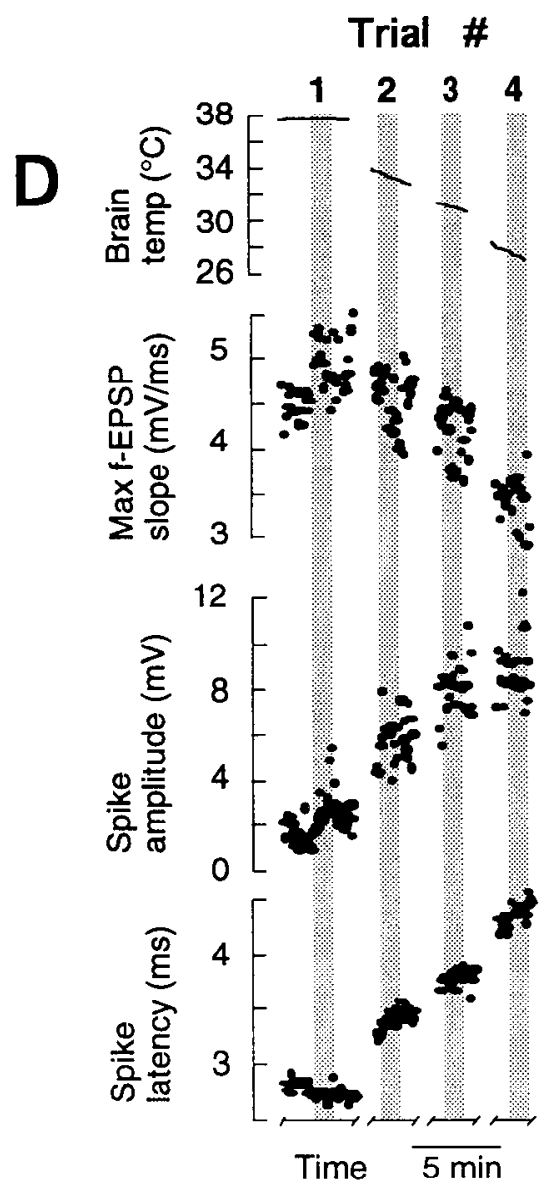

Figure 9. Simultaneously recorded swim patterns and field potentials on four consecutive spatial probe tests at four different brain temperatures (same rat). On each probe test, the platform was raised to an available, but still submerged, position after 60 sec. Brain temperature was varied from test to test. $A$, Swim paths recorded at the four temperature levels. $B$, Time spent inside circles ( $72 \mathrm{~cm}$ diameter) around the platform and around the center of each of the three other quadrants on the same four trials. $C$, Superimposed average field potentials recorded in the dentate gyrus in response to constant afferent stimulation of the perforant-path input during these probe trials. The potential taken at $38.4^{\circ} \mathrm{C}$ is shown as a broken line. $D$, The brain temperature as well as the maximum f-EPSP slope and the amplitude and latency of the population spike as a function of time on the four tests with the platform in the lowered position. Each point represents a single field potential. The shaded bars indicate the swimming periods. Potentials were also recorded during the minute before and the minute after swimming, while the rat was resting inside its home cage.

tivational requirements are similar to those of the spatial version of the test. The construction of the platform (a disk on a narrow cylinder) enhanced the difficulty to climb onto the platform.

The five rats in the $29^{\circ} \mathrm{C}$ group had brain temperatures from $28.6^{\circ} \mathrm{C}$ to $30.1^{\circ} \mathrm{C}$ at the start of this test. Only one of them was able to climb the platform (after $17 \mathrm{sec}$ ) on the first trial (Fig. $8 A, B)$. No animals entered the platform on trials 2,3 , or 4 . Another rat, starting at $32.0^{\circ} \mathrm{C}$, failed on all trials, whereas one rat released at $33.4^{\circ} \mathrm{C}$ entered the platform on the two first trials (after $8 \mathrm{sec}$ and $118 \mathrm{sec}$, respectively) but failed on trials 3 and 4. In contrast, all five rats in the $36^{\circ} \mathrm{C}$ group, having start temperatures above $35.7^{\circ} \mathrm{C}$, entered the platform rapidly (latencies below $7 \mathrm{sec}$ on trials $1-3$ ). One of these rats failed on the fourth trial.

To evaluate the relative roles of motor, sensory, or motivational dysfunction for the impaired performance on the visibletarget test, we measured the time taken to reach a circle (radius . of $26 \mathrm{~cm}$ ) around the platform center and the distance covered to this point. All rats reached this borderline within a few seconds on the first trial with the visible platform (Fig. 8C,D). The $29^{\circ} \mathrm{C}$ rats, which had the longest latencies, used $8.4 \pm 2.5 \mathrm{sec}$ and swam $2.5 \pm 0.5 \mathrm{~m}$. Their latency and swim-path length were not different from those of the rats in the $36^{\circ} \mathrm{C}$ group on trial 1 [ $t$ values $(8)<1.8, p$ values $>0.1$ ], although the latency and distance values increased across trials in the former rats. These observations suggest that sensory and motivational functions were left largely intact by the cooling.

\section{Simultaneous recording of field potentials and brain temperature on spatial probe tests}

The effect of brain cooling on field potentials in naive swimming rats and the failure to affect learning in a water-maze task were obtained in different rats. For completeness, we recorded both brain temperature and dentate field potentials in two rats while they were searching for the hidden platform on four consecutive $60 \mathrm{sec}$ spatial probe tests at four different brain temperatures. These tests were conducted after session 11 .

Figure 9 shows the results for onc of the rats. At the threc highest start temperatures $\left(38.4^{\circ} \mathrm{C}, 34.7^{\circ} \mathrm{C}\right.$, and $\left.31.8^{\circ} \mathrm{C}\right)$, the rat swam more inside the circle around the platform (10.1 sec, 23.1 $\mathrm{sec}$, and $11.8 \mathrm{sec}$, respectively) than in the other circles (averages from $3.5 \mathrm{sec}$ to $4.6 \mathrm{sec}$ ). The spatial bias disappeared only when the rat started at $28.4^{\circ} \mathrm{C}$. At that brain temperature, the rat did not even enter the platform area. In spite of unimpaired spatial 
search behavior, the cooling markedly slowed the field potentials and enhanced the population spike both at $34.7^{\circ} \mathrm{C}$ and $31.8^{\circ} \mathrm{C}$. The f-FPSP slope decreased. A similar dissociation of field potentials and learning was seen in the second rat. This rat still showed spatial bias toward the platform area at $32^{\circ} \mathrm{C}$ when the spike latency was delayed by $0.71 \mathrm{msec}$.

\section{Discussion}

The present experiments gave two main findings. First, adequate spatial learning occurred across a wide range of brain temperatures $\left(32-39^{\circ} \mathrm{C}\right)$. Within this range, there was no optimal temperature for learning. Second, there were large temperatureevoked alterations in hippocampal field potentials at temperatures that did not affect spatial learning. This may suggest that the CNS must be tolerant to considerable slowing of synaptic activation when learning takes place.

\section{Efficient learning can occur within a wide range of brain temperatures}

Spatial learning in the water maze was equally efficient in all rats acquiring the task at brain temperatures between $30-32^{\circ} \mathrm{C}$ and $39^{\circ} \mathrm{C}$. Rats starting water-maze swimming at temperatures below $30^{\circ} \mathrm{C}$ failed to search efficiently. This is consistent with previous experiments on spatial learning during severe hypothermia. Cooling rats to body temperatures below $30^{\circ} \mathrm{C}$ impairs retention of a spatial water-maze task acquired under normothermic conditions (Panakhova et al., 1984; Rauch et al., $1989 \mathrm{a})$. Conversely, extreme $\left(42^{\circ} \mathrm{C}\right)$, but not moderate $\left(38-40^{\circ} \mathrm{C}\right)$, hyperthermia has been reported to interfere with learning in a water-maze (Rauch et al., 1989b) and in a shuttle-box avoidance task (Ahlers and Riccio, 1987). It is premature, however, to interpret these temperature-rclated impairments in terms of a learning deficit. Cooling-induced performance deficits may reflect an increase of the energy expenditure required for a given amount of work (Brotherhood, 1973). Muscle cooling, increased muscle and joint viscosity, and higher conduction times cause slowness of movement and decreased skill when temperature falls (Barcroft and Edholm, 1945; Clark and Edholm, 1985). Rats performing at temperatures below $30^{\circ} \mathrm{C}$ do have motor deficiencies. Like previous investigators (Rauch et al., 1989a; Vanderwolf, 1991), we have observed that they swim slower and often fail when trying to climb an elevated visible platform. Stereotypic behavior in the form of looping along the perimeter of the pool has been reported in rats swimming at body temperatures of $23-27^{\circ} \mathrm{C}$ (Whishaw and Vanderwolf, 1971) or starting at $28^{\circ} \mathrm{C}$ or $30^{\circ} \mathrm{C}$ (Rauch et al., 1989a). The latter behavior was observed in rats swimming in water $18^{\circ} \mathrm{C}$ or lower, predicting that body and brain temperature fell further during performance of the task. Looping was not common in the coldest rats of the present experiment, possibly because their brain temperature did not fall below $29^{\circ} \mathrm{C}$ during the trial (Fig. 1).

There are, in fact, several indications that learning can take place even at brain temperatures below $30^{\circ} \mathrm{C}$. Cooling rats to rectal temperatures between $25^{\circ} \mathrm{C}$ and $31^{\circ} \mathrm{C}$ prolonged escape latencies in a water maze only transiently (Panakhova et al., 1984). Bar pressing for heat reinforcement was spared at rectal temperatures ahove $25^{\circ} \mathrm{C}$ (Panuska and Popovic, 1965). Rats trained at $28^{\circ} \mathrm{C}$ on a shock-motivated $\mathrm{T}$-maze task perform adequately when tested as hypothermic (Santucci and Riccio, 1986). Although the brain temperature does not follow the rectal temperature exactly, it was most likely reduced to within $2^{\circ} \mathrm{C}$ of the latter (Moser, Mathiesen, and Andersen, unpublished observations). In the present experiment, the precision of the search behavior of the group with a brain temperature of $29^{\circ} \mathrm{C}$ was clearly reduced. However, these rats did, in fact, swim in the correct half of the pool at the end of the training. Thus, some learning may be possible even below $30^{\circ} \mathrm{C}$ in rats. Because we did not find an optimal temperature for spatial learning, it is unlikely that behaviorally induced temperature changes are an important modulator of learning (Göpfert et al., 1953). The actual temperature range during which lcarning can take place may be different in primates. In humans, progressive impairment of reasoning and memory has been observed at rectal temperatures below $34^{\circ} \mathrm{C}$ (Fay and Smith, 1941). There was retrograde amnesia for events that occurred during cooling below this temperature.

\section{Temperature reduction slows down synaptic transmission without affecting learning}

The present experiments show that learning and retention are remarkably efficient even on tests where field potentials in the dentate gyrus show large changes. The f-EPSP decreases following cooling of the brain, but the reduction is often partly counteracted by a moderate temperature-independent synaptic enhancement (Fig. 2). This enhancement is also seen during exploration and may be related to learning (Moser et al., 1993c). In contrast to the f-EPSP, the population spike shows a marked temperature-related enhancement and can be delayed by at least $1 \mathrm{msec}$ at reduced brain temperatures at which learning is preserved (Figs. 2, 9). After a brain temperature decrease of $2^{\circ} \mathrm{C}$, the population spike increase is larger than any temperatureindependent change in field potentials resulting from behavior alone (Moser et al., 1993c). In spite of such considerable changes, the rats do learn the spatial task.

Although temperature-induced changes of dentate field potentials are a highly regular observation, it is not straightforward to assess the significance of these changes. The slowing of the f-EPSP during cooling indicates that the mean intracellular EPSP rises less rapidly, but the amplitude may well reach the same level as before. The slower rise time leads to a delayed discharge of the target cells, as is also indicated by the increased population spike latency. Whether the delayed discharge to synaptic activation is coupled to a changed probability of discharge as well is unknown. The increased population spike during cooling cannot be taken as a sign of an increased number of cells firing, as is the case at constant temperature (Andersen et al., 1971). The reason is that reduced temperature results in an artifactual increase of all electrical signals (Ritchie and Straub, 1956; Andersen et al., 1972) due to three factors: cooling gives larger individual action potentials (Schoepfle and Erlanger, 1941; Hodgkin and Katz, 1949), a depolarization of the membrane (Hodgkin and Katz, 1949), and a more efficient summation of individual signals to a compound potential (Ritchie and Straub, 1956; Andersen, 1960; Andersen et al., 1972). In the cuneate nucleus, the N-wave, which is a blend of summed f-EPSPs and action potentials, shows a prominent increase on cooling the nucleus (Andersen et al., 1972). In contrast, the probability of discharge of cuneate neurons was only weakly affected by gentle cooling (about $5^{\circ} \mathrm{C}$ ), but on more intense cooling (from $37^{\circ} \mathrm{C}$ to $26^{\circ} \mathrm{C}$ ) there was a reduction by $20 \%$ of the discharge probability of individual units. Thus, an enhanced population spike during cooling cannot be taken as evidence for an increased number of cells being activated by the test afferent volley. Rather, it is 
more likely that the number of discharging cells is slightly reduced.

The slowing of the field potentials suggests that the relative timing of synaptic events in the cooled brain must be significantly altered. The dispersion of these events should increase with increasing numbers of synapses in a neuronal chain, probably causing significant changes of timing in complex networks of neurons. In spite of such slowing of information transfer, the rats were still able to learn, suggesting that the combinations of impulses necessary for learning in a water maze still take place. The speed of the combinations is, however, likely to be reduced.

In conclusion, the main effect of temperature reduction may be a slowing of most parts of neuronal transmission. Provided that the consequent change in the relative timing of cellular events is equally distributed in all relevant circuits, which is a likely proposal, all combinations may occur as in the warmer brain, but at a somewhat slower speed. Only during severe hypothermia $\left(30^{\circ} \mathrm{C}\right.$ or lower) may disruption of hippocampal synaptic transmission jeopardize information handling and thereby reduce the efficiency of spatial learning. Thus, the present results suggest that memory is encoded by mechanisms that are relatively insensitive to the speed of impulse transmission across hippocampal synapses.

\section{References}

$\Lambda$ brams R, Hammel HT (1964) Hypothalamic tempcraturc in unanesthetized albino rats during feeding and sleeping. Am J Physiol 206:641-646.

Abrams R, Hammel HT (1965) Cyclic variations in hypothalamic temperature in unanesthetized rats. Am J Physiol 208:698-702.

Ahlers ST, Riccio DC (1987) Anterograde amnesia induced by hyperthermia in rats. Behav Neurosci 101:333-340.

Andersen P (1960) Interhippocampal impulses. III. Basal dendritic activation of CA3 neurons. Acta Physiol Scand 48:209-230.

Andersen P, Bliss TVP, Skrede KK (1971) Unit analysis of hippocampal population spikes. Exp Brain Res 13:208-221.

Andersen P, Gjerstad L, Pasztor E (1972) Effect of cooling on synaptic transmission through the cuneate nucleus. Acta Physiol Scand 84: 433-447.

Barcroft H, Edholm OG (1945) Temperature and blood flow in the human forearm. J Physiol (Lond) 104:366-376.

Brotherhood JR(1973) Studies in energy expenditure in the Antarctic. In: Polar human biology (Edholm OG, Gunderson EKE, eds), pp 182-192. London: Heinemann Medical.

Buresova O, Bolhuis JJ, Bures J (1986) Differential effects of cholinergic blockade on performance of rats in the water tank navigation task and in a radial water maze. Behav Neurosci 100:476-482.

Clark RP, Edholm OG (1985) Man and his thermal environment. London: Arnold.

Fay T, Smith GW (1941) Observations on reflex responses during prolonged periods of human refrigeration. Arch Neurol Psychiatry $45: 215-222$.

Göpfert H, Bernsmeier A, Stufler R (1953) Über die Steigerungen des Energiestoffwechsels und der Muskclinncrvation bci geistigcr Arbeit. Pfluegers Arch 256:304-320.

Gordon CJ (1990) Thermal biology of the laboratory rat. Physiol Behav 47:963-991.

Hodgkin AL, Katz B (1949) The effect of temperature on the electrical activity of the giant axon of the squid. J Physiol (Lond) 109:240-249.

Huynh H, Feldt LS (1976) Estimation of the box correction for degrees of freedom from sample data in the randomized block and split-plot designs. J Educ Statist 1:69-82.

Katz B, Miledi R (1965) The effect of temperature on the synaptic delay at the neuromuscular junction. J Physiol (Lond) 181:656-670.
Lewis DJ, Jackson F, Miller RR, Misanin JR (1972) The relation between rectal and brain temperatures following hypothermia. Psychon Sci 27:29-30.

Markowska AL, Long JM, Johnson CT, Olton DS (1993) Variableinterval probe test as a tool for repeated measurements of spatial memory in the water-maze. Behav Neurosci 107:627-632.

Morris RGM (1984) Developments of a water-maze procedure for studying spatial learning in the rat. J Neurosci Methods 11:47-60.

Morris RGM, Garrud P, Rawlins JNP, O'Keefe J (1982) Place navigation impaired in rats with hippocampal lesions. Nature 297:681683.

Morris RGM, Kandel FR, Squire LR (1988) The neuroscience of learning and memory: cells, neural circuits and behavior. Trends Neurosci 11:125-127.

Morris RGM, Schenk F, Tweedie F, Jarrard LE (1990) Ibotcnatc lesions of hippocampus and/or subiculum: dissociating components of allocentric spatial learning. Eur J Neurosci 2:1016-1028.

Moser E, Mathiesen I, Andersen P (1993a) Association between brain temperature and dentate field potentials in exploring and swimming rats. Science 259:1324-1326.

Moser E, Moser MB, Andersen P (1993b) Spatial learning impairment parallels the magnitude of dorsal hippocampal lesions, but is hardly present following ventral lesions. J Neurosci 13:3916-3925.

Moser E, Moser MB, Andersen P (1993c) Synaptic potentiation in the rat dentate gyrus during exploratory learning. Neuroreport 5:317320.

Nielsen B (1988) Natural cooling of the brain during outdoor bicycling? Pfluegers Arch 411:456-461.

Panakhova E, Buresova O, Bures J (1984) The effect of hypothermia on the rat's spatial memory in the water tank task. Behav Neural Biol 42:191-196.

Panuska JA, Popovic VP (1965) Critical temperature for instrumental response acquisition in hypothermic rats. J Appl Physiol 20:12751277.

Rauch TM, Welch DI, Gallego L (1989a) Hypothermia impairs performance in the Morris water maze. Physiol Behav 45:315-320.

Rauch TM, Welch DI, Gallego L (1989b) Hyperthermia impairs retrieval of an overtrained spatial task in the Morris water maze. Behav Neural Biol 52:321-330.

Ritchie IM. Straub RW (1956) The effect of cooling on the size of the action potential of mammalian non-medullated fibres. J Physiol (Lond) 134:712-717.

Santucci AC, Riccio DC (1986) Hypothermia-induced anterograde amnesia and its reversal in rats trained on a $\mathrm{T}$-maze escape task. Physiol Behav 36:1065-1069.

Schiff SJ, Somjen GG (1985) Effects of temperature on synaptic transmission in hippocampal tissue slices. Brain Res 345:279-284.

Schoepfle GM, Erlanger J (1941) The action of temperature on the excitability, spike height and configuration, and the refractory period observed in the responses of single medullated nerve fibers. Am J Physiol 134:694-704.

Sutherland RJ, Whishaw IQ, Kolb B (1983) A behavioural analysis of spatial localization following electrolytic, kainate or colchicineinduced damage to the hippocampal formation in the rat. Behav Brain Res 7:133-153.

Vanderwolf CH (1991) Effects of water temperature and core temperature on rat's performance in a swim-to-platform test. Behav Brain Res 44:105-106.

Vasey MW, Thayer JF (1987) The continuing problem of false positives in repeated measures ANOVA in psychophysiology: a minultivariate solution. Psychophysiology 24:479-486.

Whishaw IQ, Vanderwolf $\mathrm{CH}$ (1971) Hippocampal EEG and behavior: effects of variation in body temperature and relation of $\mathrm{EEG}$ to vibrissae movement, swimming and shivering. Physiol Behav 6:391397.

Winer BJ, Brown DR, Michels KM (1991) Statistical principles in experimental design, 3d ed. New York: McGraw-Hill.

Zilles K (1985) The cortex of the rat. A stereotaxic atlas. Berlin: Springer. 